\title{
Large-Scale Flow Patterns Associated with Extreme Precipitation and Atmospheric Rivers over Norway
}

\author{
IMME BENEDICT \\ Meteorology and Air Quality Group, Wageningen University, Wageningen, Netherlands \\ KARIANNE ØDEMARK AND THOMAS NIPEN \\ Norwegian Meteorological Institute, Oslo, Norway \\ RICHARD MOORE \\ Norwegian Meteorological Institute, and University of Oslo, Oslo, Norway
}

(Manuscript received 12 October 2018, in final form 4 February 2019)

\begin{abstract}
A climatology of extreme cold season precipitation events in Norway from 1979 to 2014 is presented, based on the 99th percentile of the 24-h accumulated precipitation. Three regions, termed north, west, and south are identified, each exhibiting a unique seasonal distribution. There is a proclivity for events to occur during the positive phase of the NAO. The result is statistically significant at the 95th percentile for the north and west regions. An overarching hypothesis of this work is that anomalous moisture flux, or socalled atmospheric rivers (ARs), are integral to extreme precipitation events during the Norwegian cold season. An objective analysis of the integrated vapor transport illustrates that more than $85 \%$ of the events are associated with ARs. An empirical orthogonal function and fuzzy cluster technique is used to identify the large-scale weather patterns conducive to the moisture flux and extreme precipitation. Five days before the event and for each of the three regions, two patterns are found. The first represents an intense, southward-shifted jet with a southwest-northeast orientation. The second identifies a weak, northwardshifted, zonal jet. As the event approaches, regional differences become more apparent. The distinctive flow pattern conducive to orographically enhanced precipitation emerges in the two clusters for each region. For the north and west regions, this entails primarily zonal flow impinging upon the south-northorientated topography, the difference being the latitude of the strong flow. In contrast, the south region exhibits a significant southerly component to the flow.
\end{abstract}

\section{Introduction}

Extreme precipitation events in Norway are often the result of anomalously large moisture fluxes impinging upon the complex mountainous terrain. Azad and Sorteberg (2017), Sodemann and Stohl (2013), and Stohl et al. (2008) have shown how so-called atmospheric rivers (ARs), long narrow regions of intense water vapor transport within the lower atmosphere, are integral to the transport of (sub and extra) tropical moisture to Norwegian latitudes. Their studies incorporated a variety of techniques (synoptic analyses, clustering, tracer transport), datasets (surface observations, model operational and reanalysis data), and time frames (single events to a

Corresponding author: Imme Benedict, imme.benedict@wur.nl century) to imply that the connection of integral water vapor transport and ARs is a robust result and to identify possible large-scale structures that are conducive to these events. Using the previous work as a foundation, the overarching goal of this work is to use a cohesive longterm dataset (reanalysis data) to identify a large number of extreme precipitation events to better understand the climatology and processes at work.

ARs are a key component to the global water cycle (Zhu and Newell 1998) and to regional extreme precipitation (Knippertz and Wernli 2010; Leung and Qian 2009; Ralph et al. 2006; Stohl et al. 2008). As such, ARs can strongly affect short-term weather and flood prediction, as well as seasonal climate anomalies (Ralph et al. 2004). In regards to the latter, Stohl et al. (2008) note that the large moisture fluxes are relatively more 
important during the positive phase of the North Atlantic Oscillation in Norway, associated with the increased storminess in general during this phase. This result implies relevance to seasonal predictability. Furthermore, other work has shown that there remain large uncertainties regarding quantitative precipitation forecasts under climate change scenarios, making a better understanding of precipitation processes vital for future climate services to properly predict extreme precipitation events (Dettinger 2011; Ralph et al. 2011).

An example of a Norwegian extreme precipitation event on 13 September 2005 was examined by Stohl et al. (2008). Vertically integrated water vapor images clearly identify a coherent, narrow plume of moisture extending from the tropics and subtropics to southwestern Norway. The moisture transport along this plume was found to play a critical role in producing orographically enhanced precipitation resulting in landslides and flooding that caused considerable damage to property and life. Further corroborative work regarding the importance of orographic enhancement can be found here (Bader and Roach 1977; Browning and Pardoe 1973; Harrold 1973).

An intriguing comparison is found in the North Pacific, where moisture plumes have been linked to extreme precipitation in western North America. The apparent dynamical similarity in the two ocean basins implies the North Pacific and North America research is likely relevant for extreme precipitation in Norway. An extensive series of research in this region (Ralph et al. 2004, 2006, 2011; Wick et al. 2013) incorporating some combination of in situ aircraft observations, satellite data, coastal wind profilers and GPS meteorological stations, gridded precipitation data, global reanalysis data, and operational ensemble prediction systems can be summarized in the following key findings: (i) the overwhelming majority of extreme precipitation events are associated with ARs, (ii) forecasts of landfalling ARs and their characteristics are significantly poorer than that of the large-scale patterns related to the $\mathrm{AR}$, and (iii) quantitative precipitation forecasts (QPFs) improve with shorter forecast length, yet significant biases exist and biases can and do exhibit a strong sensitivity to the local geography. The overarching conclusion can be stated thusly: to properly capture extreme precipitation events, the large-scale flow patterns on scales from planetary to the mesoscale need to be well resolved to provide an accurate forecast of the location and intensity of the extreme precipitation (Ralph and Dettinger 2011).

The analyses of Azad and Sorteberg (2017), Heikkilä and Sorteberg (2012), Sodemann and Stohl (2013), and Stohl et al. (2008) centered on Norway in conjunction with similar work focusing on Great Britain and northern Europe (Knippertz and Wernli 2010; Lavers et al. 2011; Lavers and Villarini 2013; McTaggart-Cowan et al. 2017; Ummenhofer et al. 2017) provide compelling evidence for the causal link between large-scale moisture transport and extreme precipitation in Norway.

The objectives of this work are to (i) systematically identify extreme precipitation events using a cohesive long-term dataset of 36 years; (ii) explore their seasonal, intraseasonal, and geographic variability; (iii) test the connection to ARs on the identified dataset of events; and (iv) use fuzzy clustering to examine their large-scale patterns. This work will contribute to an improved understanding of the climatology and processes leading to extreme precipitation along the coastline in Norway, which can eventually lead to more accurate forecasts that can mitigate damage to life and property.

The outline of this paper is as follows. After a description of the data and methodology (section 2), a climatology of extreme precipitation events will be presented in section $3 \mathrm{a}$. Section $3 \mathrm{~b}$ will examine the large-scale atmospheric structures that lead to the anomalous moisture flux that is integral to extreme precipitation in Norway. Finally, study conclusions are presented in section 4 .

\section{Data and methodology}

\section{a. Data}

The primary data source for this study is the European Centre for Medium-Range Weather Forecasts (ECMWF) interim reanalysis (ERA-Interim; Dee et al. 2011) from 1979 to 2014. The precipitation analysis is performed on a grid of $0.25^{\circ}$ latitude by $0.25^{\circ}$ longitude over Norway, which is a bilinear interpolated field from the original $0.75^{\circ}$ latitude by $0.75^{\circ}$ longitude resolution of ERA-Interim. To examine large-scale dynamic patterns, ERA-Interim data are obtained on a grid of $0.75^{\circ}$ latitude by $0.75^{\circ}$ longitude over the Atlantic basin $\left(20^{\circ}-80^{\circ} \mathrm{N}, 70^{\circ} \mathrm{W}-20^{\circ} \mathrm{E}\right)$. Relevant variables that are examined are the (i) potential temperature along the dynamic tropopause (defined as the two potential vorticity unit surface), (ii) integrated vapor transport, (iii) mean sea level pressure, and (iv) daily total accumulated precipitation (calculated by summing the 12-h forecasted precipitation during 0000-1200 and 1200-2400 UTC).

\section{b. Climatology of extreme precipitation events}

A climatology of extreme Norwegian precipitation is constructed based upon the 99th percentile of daily precipitation amounts during the 1979-2014 time period (see Fig. 1a). Figure 1b shows the topography of 

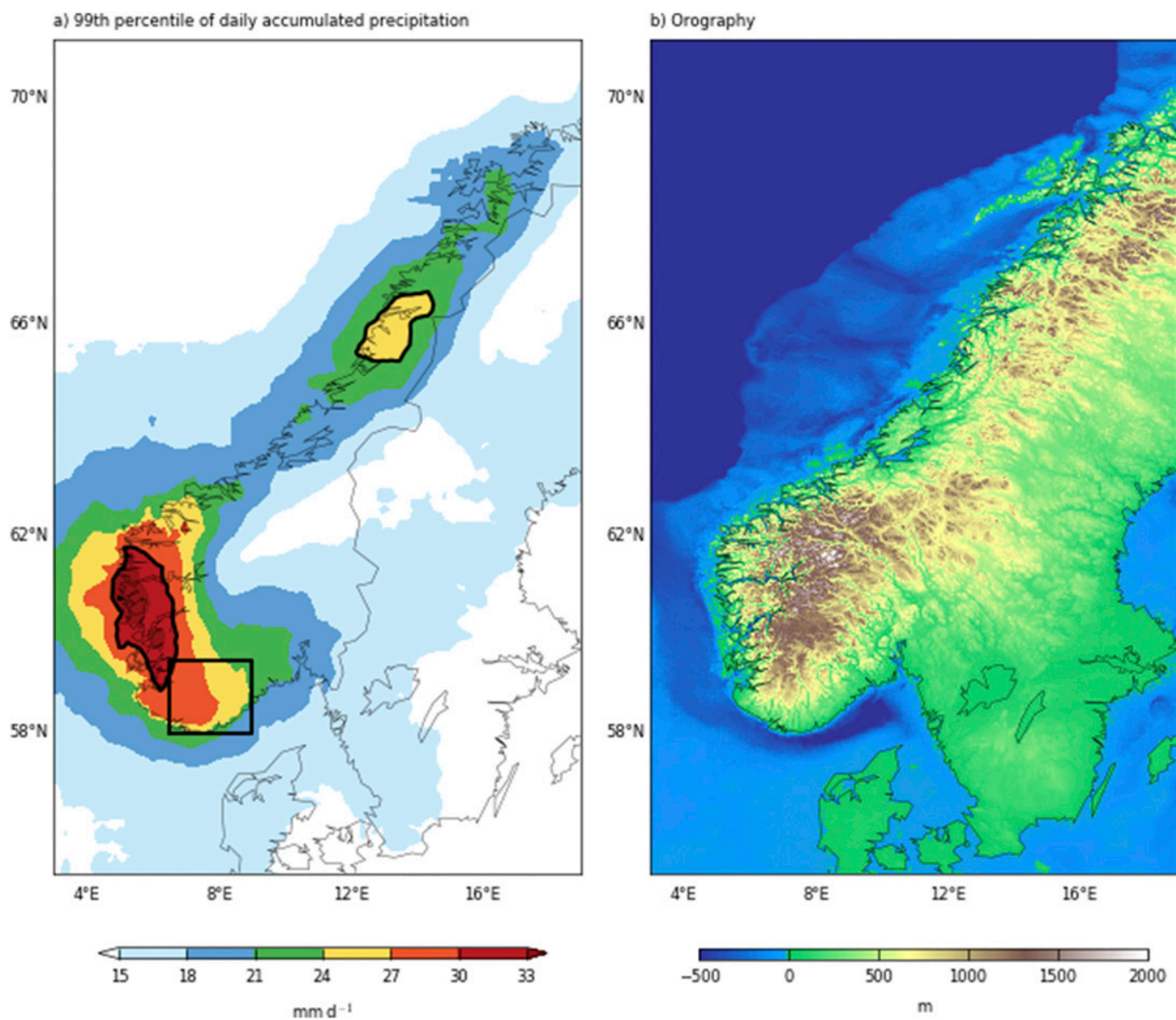

FIG. 1. (a) The 99th percentile of daily accumulated precipitation over Norway in $\mathrm{mm} \mathrm{day}^{-1}$. Regions defined as west and north Norway are defined with the 30 and $24 \mathrm{~mm}$ day $^{-1}$ contour line, respectively. South Norway is defined with the indicated black box. (b) The elevation of our study area in $\mathrm{m}$.

Norway. Distinct maxima of precipitation are identified in north and southwest Norway via a closed contour of enhanced precipitation (24 and $30 \mathrm{~mm}$ day $^{-1}$, respectively, see black contour lines). A southern region is subjectively identified in the absence of a climatological maximum, based upon an examination of previous extreme storm reports that indicate a different flow pattern for storms in this region. The region is represented by the black box in Fig. 1 and ranges from $6.5^{\circ}$ to $9^{\circ} \mathrm{E}$ and from $58^{\circ}$ to $59.5^{\circ} \mathrm{N}$. The results of this work make a strong argument for the distinction of this southern region. The three regions will hereafter be referred to as north, west and south Norway, respectively. For each region, all dates with area-averaged daily precipitation exceeding the 99th percentile are selected as extreme precipitation events.

To objectively identify atmospheric rivers, the definition introduced by Rutz et al. (2014) is employed. This definition is based on the vertically integrated horizontal water vapor flux [integrated vapor transport (IVT)] and is defined as

$$
\mathrm{IVT}=\frac{1}{g} \int_{p_{1000 \mathrm{~Pa}}}^{p_{100 \mathrm{PPa}}} q \mathbf{V} d p
$$

where $g$ is the gravitational acceleration, $q$ is the specific humidity, $\mathbf{V}$ is the total wind vector wind, and $p$ is pressure. The integration is computed using $50-\mathrm{hPa}$ intervals from 1000 to $500 \mathrm{hPa}$, and $100-\mathrm{hPa}$ intervals from 500 to $100 \mathrm{hPa}$.

ARs are identified when the IVT exceeds the threshold of $250 \mathrm{~kg} \mathrm{~m}^{-1} \mathrm{~s}^{-1}$ for a contiguous length of $\geq 2000 \mathrm{~km}$ (Rutz et al. 2014). IVT objects are identified when they intersect the respective precipitation region. If the above criteria are met at any of the four time steps $(0000,0600$, 1200 , and 1800 UTC) during the day of the event, it is deemed to be associated with an AR.

A primary focus of this work is to study the large-scale patterns related to moisture transport and extreme 
precipitation events over Norway. Such events are typically characterized by a persistent flow (on the order of 24-72 h) of warm moist air impinging on mountainous terrain. To avoid including warm season, convective events (on the order of one to a few hours) only cases occurring during the cold season (defined here as September to March) are used for further analysis. Furthermore, to avoid "counting" a multiday event more than once, events that occur on consecutive days are parsed to solely the day of the most extreme precipitation. The rationale is that the multiday events are associated with a similar large-scale pattern.

\section{c. Statistical and composite analysis}

To study the variability in the large-scale preconditioning of the events, a two-step procedure is employed. Step one is an empirical orthogonal function (EOF) analysis of the potential temperature on the dynamic tropopause (defined as the two potential vorticity unit surface) over the large domain $\left(20^{\circ}-80^{\circ} \mathrm{N}, 70^{\circ} \mathrm{W}-\right.$ $20^{\circ} \mathrm{E}$ ). The EOF analysis will detect the underlying structure that best explains the variability in a multivariate dataset (Richman 1986). Information on the dynamic tropopause was chosen due to the fact that AR structure and evolution are tightly coupled to the predominant circulation patterns on the synoptic scale, including the location, strength and shape of the upper-level flow at tropopause level (Sodemann and Stohl 2013).

In step two a fuzzy cluster analysis is incorporated, based on the first two principal components of the EOF analysis, to partition events into groups with similar large-scale structure. The analyses are conducted separately for each of the three regions and for different time steps ahead of the event (24-h intervals beginning $120 \mathrm{~h}$ before the event, including the day of the event itself). All analyses are performed at 1200 UTC.

This method is thoroughly described and has been successfully applied by Harr et al. (2008) with respect to the extratropical transition of the west North Pacific Typhoon Nabi (September 2005). Their goal was to examine the predictability of the event in ECMWF ensemble forecast data. Here, in contrast, ERA-Interim data are used to determine the variability between the large-scale atmospheric patterns of many events as opposed to ensemble members for a singular event.

For the fuzzy cluster analysis, the number of clusters is a subjective choice based on the level of precision or detail desired (Harr et al. 2008). This analysis incorporates the first two principal components (PCs) from the EOF analysis. The clustering procedure randomly places centers of the number of clusters chosen in the PC1-PC2 phase space, as a first guess. Each event member is also placed in the PC1-PC2 phase space, and thus represented by the pair of PC values. Every event member is attributed to the nearest cluster center. To find the solution with shortest distances between members and cluster centers, the analyses iterate and calculate new cluster centers. Each point is evaluated again in every iteration. When the distance to the cluster centers is minimized a stable solution is found and the iteration ceases.

Here, both two and three-cluster solutions for all regions at the different times before the event were created. After an in-depth examination of the data, we believe that the two-cluster solution is more appropriate for this study because (i) the detail added by the threecluster solution is deemed insufficient to justify the increase in complexity; (ii) cluster members were more coherent over time with the two-cluster solution, in that the majority of events remained in the same cluster for the $120 \mathrm{~h}$ leading to the event; and (iii) the choice of a two-cluster solution allows for a direct comparison with the work of Sodemann and Stohl (2013) wherein they identified two moisture transport configurations for the month of December 2006; a month characterized by well above average temperature and precipitation in Norway. The latter is especially appealing in that Sodemann and Stohl (2013) equated the two patterns to the known characteristic life cycles of baroclinic waves (Thorncroft et al. 1993), providing a valuable dynamical distinction.

Subsequent to the cluster analysis, the composite structure of the clustered members is constructed. These composites can be created for any meteorological variable of interest. Finally, the cluster members are established at $120 \mathrm{~h}$ before the event and remain the same until the event itself. We believe this is justifiable based on point (ii) above.

\section{Results}

\section{a. Extreme precipitation climatology}

The results of the climatological analysis of extreme precipitation are presented in this section. With the omission of multiday events, the total cold season event counts are 101, 118, and 101 for the north, west and south regions, respectively. The fraction of events per month for the three regions is presented in Fig. 2. The area-averaged value of the 99th percentile for each month and region is provided on top of the bars in Fig. 2.

Each of the three regions exhibit a characteristic seasonal variability, providing further motivation for the selection of three distinct regions. For north Norway, 


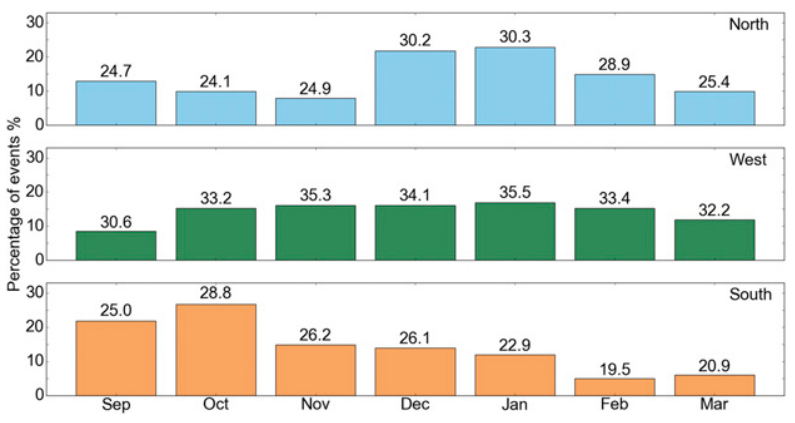

FIG. 2. Histogram with monthly climatology for the selected events for every region; the $y$ axis indicates the fraction of events in that month compared with the total amount of events. Value above each bar indicates the 99th of extreme precipitation for that specific month in mm day ${ }^{-1}$.

a maximum fraction of event counts is found in December and January (22\% and $23 \%$ ), and thereafter in February and September (15\% and 13\%). There is a remarkable consistency of event counts in west Norway from October through February with no clear maximum (all around 16\%). In contrast, a fall maximum (September, 22\% and October, 28\%) and a minimum in late winter (February, $5 \%$ and March, $6 \%$ ) are observed in south Norway.

To investigate the hypothesis that different flow patterns can be identified for each region, the anomalies of mean sea level pressure (MSLP) at 1200 UTC and daily accumulated precipitation anomaly for all events in each region are presented in Fig. 3, for the day of the events. The anomalies are calculated from the average MSLP at 1200 UTC of all the events compared to the cold season average MSLP at 1200 UTC, and accordingly for daily accumulated precipitation. The stippling indicates regions where the anomaly is statistically significant at the 0.05 level according to the independent samples $t$ test. Figure 4 shows the composites of the selected events of MSLP and precipitation for the three regions.

A distinct similarity exists for all regions: the presence of a low and high pressure couplet resulting in strong inferred low-level flow oriented in such a way as to result in enhanced orographic uplift (Figs. 3b,d,f). The fundamental difference between the regions is in the position of the pressure centers. For north Norway, the couplet is meridionally aligned, leading to strong zonal flow. Southwesterly flow is observed for west Norway due to a southwestward (northeastward) shift in the low (high) pressure centers. The pattern for south Norway exhibits a low pressure center shifted to the southwest and the high pressure center located far to the southwest. The result is a significant southerly component to the inferred low-level flow. The difference in flow pattern between west and south
Norway supports the decision to include the subjectively defined south region.

The precipitation anomalies in each region are apparent. Moreover, a secondary positive anomaly over Great Britain is observed for west and south Norway. The implication is that the very same moisture flux leading to extreme precipitation in southwestern Norway is conducive to enhanced precipitation in Great Britain, a result consistent with the study of Lavers et al. (2011) who linked winter flooding in Britain to atmospheric rivers.

Also of note is the overlap of precipitation between the three regions (see Fig. 4). A clear secondary anomaly in west Norway is found in the north analysis $\left(15 \mathrm{~mm} \mathrm{day}^{-1}\right.$ in west while $30 \mathrm{~mm} \mathrm{day}^{-1}$ in north). For the west analysis, enhanced precipitation is observed in the north region $\left(10 \mathrm{~mm} \mathrm{day}^{-1}\right.$ in north while $>25 \mathrm{~mm} \mathrm{day}^{-1}$ in west). Additionally, there is a significant overlap between the west and south regions. An examination of the overlap of the events between the regions reveals that only two events are identical for the north and west region. However, there is an overlap of 15 events between the west and south regions, which is roughly $15 \%$ of the total number of selected events. While this is a significant fraction, we believe the different flow patterns observed in Figs. 3 and 4 provide compelling evidence to consider the regions separately.

\section{1) INTER-REGION CORRELATION}

To further examine the association between regions, the inter region correlation, the correlation of monthly event totals (number of events occurring per month) for regional couplets (south-west, south-north, and westnorth) was computed. Using the 0.05 threshold, the results show there is a statistically significant correlation of monthly event totals for all three couplets. The correlation was strongest for west-north (0.28) and south-west (0.27), but weaker for south-north (0.11). As seen in Fig. 3, the flow patterns for the north and west regions are most similar, which explains the strongest correlation. Less similar flow patterns are found for the couplets including the south region, especially the south-north couplet.

\section{2) INTRASEASONAL VARIABILITY}

Previous work has illustrated that extreme precipitation events are more likely during the positive phase of the NAO (Uvo 2003; Stohl et al. 2008; Brands et al. 2017). The phase and magnitude of the daily NAO index (data from the Climate Prediction Center) for the events are presented in the form of box-andwhisker plots in Fig. 5. The median value is positive for all regions. 
a) North
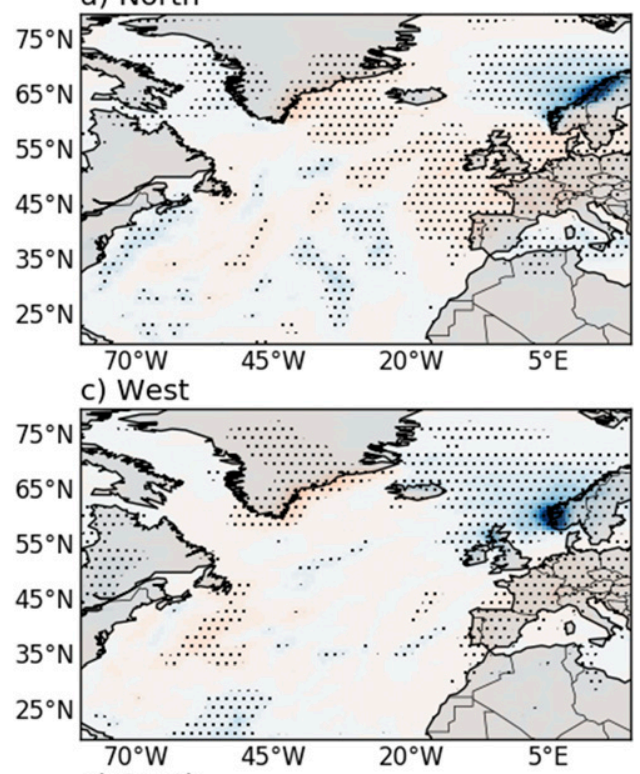

e) South

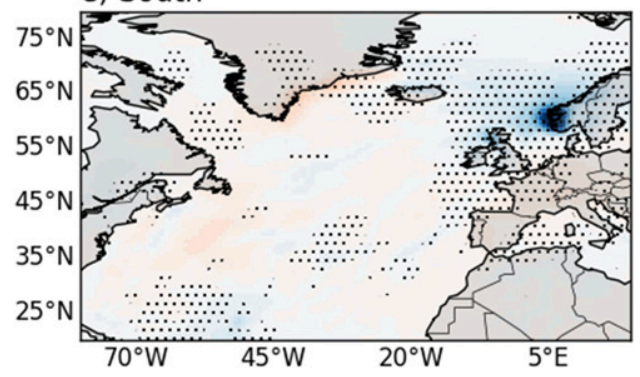

b) North

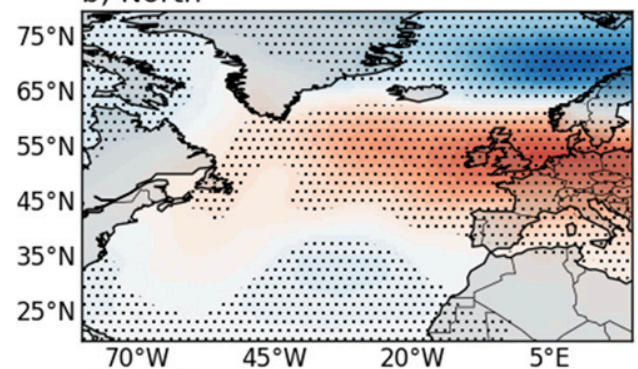

d) West

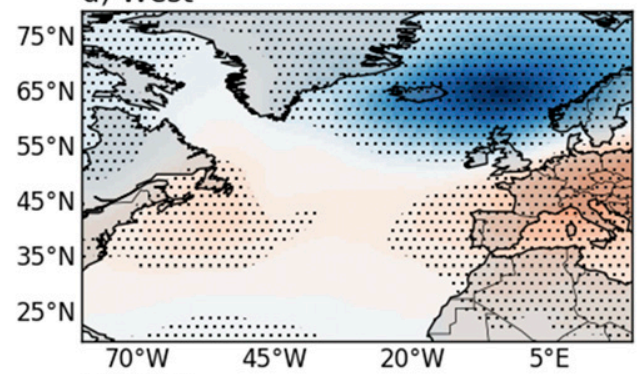

f) South

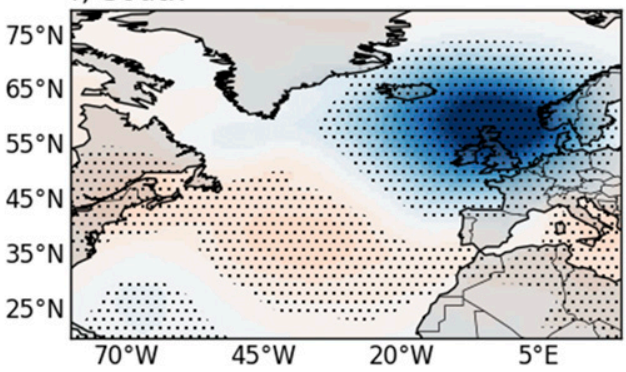

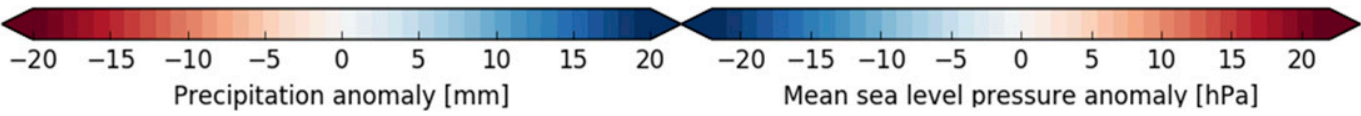

FIG. 3. (left) Precipitation anomalies (mm) for all extreme precipitation events for the (a) north region, (c) west region, and (e) south region at the day of the events. (right) Mean sea level pressure anomaly ( $\mathrm{hPa}$ ) for all the events for the (b) north region, (d) west region, and (f) south region. For all panels the dotted regions indicate where the anomaly is statistical significant.

To establish the statistical significance of this result (i.e., a positive NAO index is more likely for event days as opposed to nonevent days), an independent samples $t$ test is incorporated. The test is based on the average index value for each region as well as the standard deviation and number of events. Since the NAO index is heavily correlated in time, the number of independent data points is reduced. To account for this "serial correlation," a socalled effective sample size is introduced. The effective sample size is calculated for nonevents and events by:

$$
\hat{n}=n \frac{(1-\rho)}{1+\rho}
$$

where $n$ is the number of events and $\rho$ is the autocorrelation. The results are presented in Table 1. For nonevents, the effective sample size is reduced by roughly a factor of 15 . The reduction is much less for events, as the NAO index is less correlated between individual events.

A significance test at the 0.05 level indicates that the positive phase of the NAO during the selected extreme events (Fig. 5) is statistically significant for the north and west regions. In contrast, the significance threshold is not met for the south region.

\section{3) LINK TO ATMOSPHERIC RIVERS}

An overarching hypothesis of this work is that extreme precipitation in Norway can be directly linked to anomalously large moisture transport (Lavers and Villarini 2013). The composite magnitude and direction 

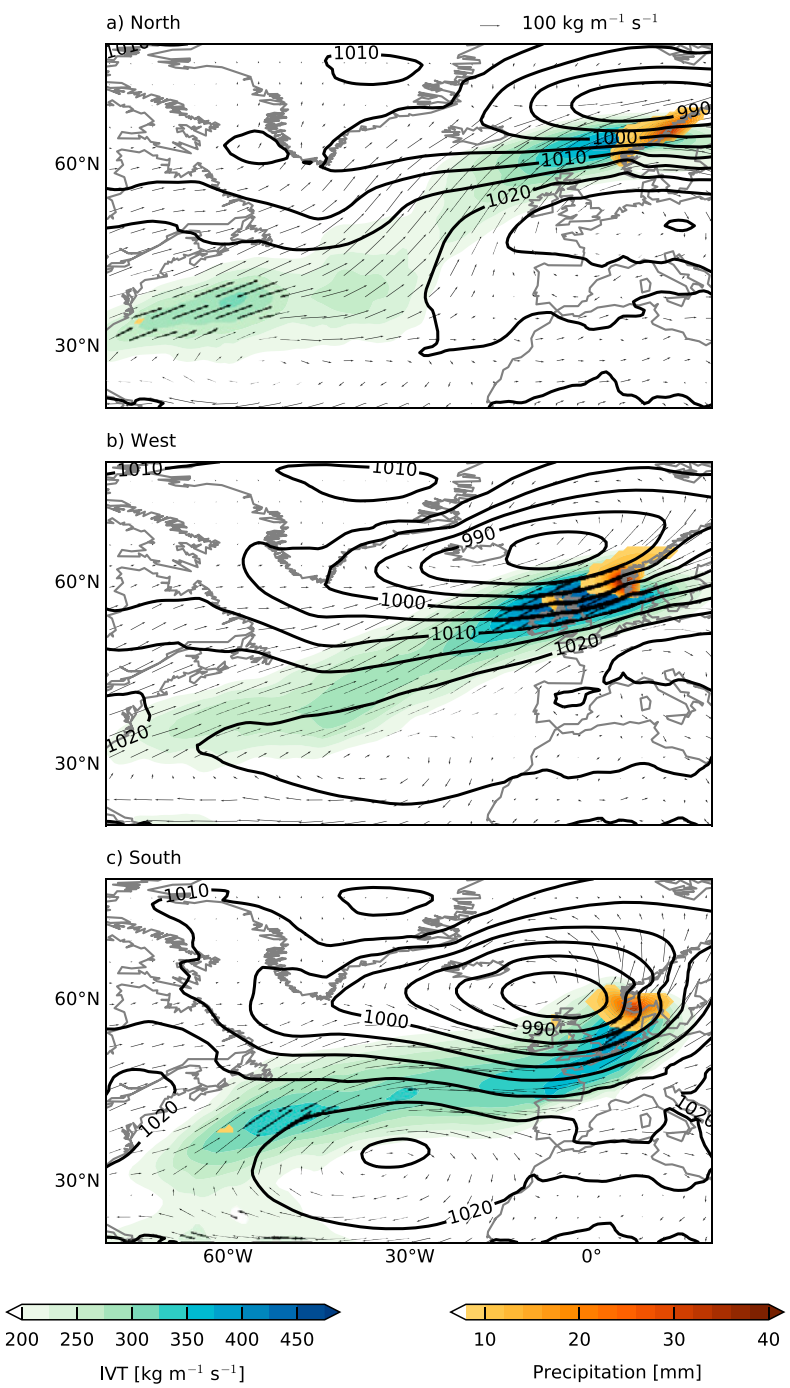

FIG. 4. Composites of mean sea level pressure $(\mathrm{hPa})$ in contours and total precipitation $(\mathrm{mm})$ in orange-red shading and IVT vectors and magnitude $\left(\mathrm{kg} \mathrm{m}^{-1} \mathrm{~s}^{-1}\right)$ in green-blue shading at the day of the events for the (a) north region, b) west region, and c) south region.

of IVT on the day of the extreme precipitation events are presented in Fig. 4. The AR-like structure is evident as a relatively narrow and elongated region of enhanced IVT for all regions. Concomitantly, the regional differences in the inferred low-level flow discussed above are apparent in the IVT vector field.

Given the climatology of events, we objectively calculate what fraction of the identified events is associated with ARs. Based on the criteria of Rutz et al. (2014), the majority of cold-season events are linked to ARs: $87 \%$, $97 \%$, and $88 \%$ of events were associated with an AR for respectively the north, west, and south regions. To test the robustness of this result, we examine the sensitivity to the IVT threshold value chosen by Rutz et al. (2014).

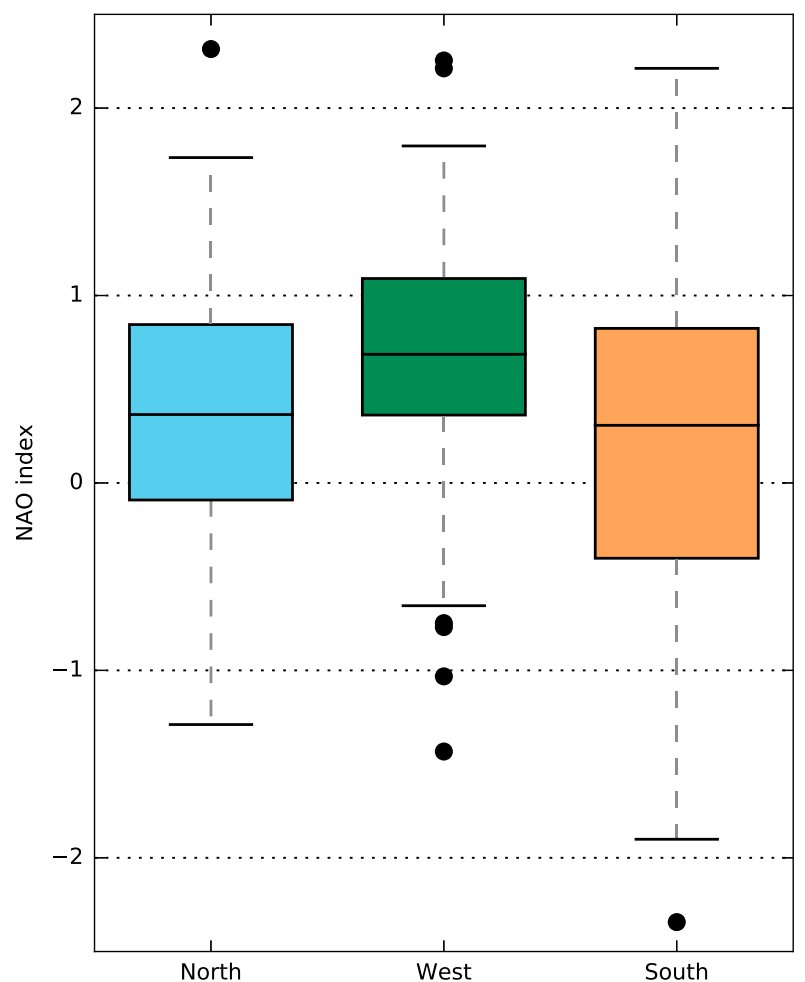

FIG. 5. Box-and-whisker plot of the NAO index of the north, west, and south regions. The boxplot shows the median, the upper quartile (Q1,75\%) and lower quartile (Q3, 25\%), the upper whisker [Q1 - $1.5 \times(\mathrm{Q} 1-\mathrm{Q} 2)]$ and the lower whisker [Q3 + $1.5 \times(\mathrm{Q} 1-\mathrm{Q} 2)]$, and the outliers (in black dots).

The above analysis is repeated by successively increasing the IVT threshold from 250 to $500 \mathrm{~kg} \mathrm{~m}^{-1} \mathrm{~s}^{-1}$ with steps of $50 \mathrm{~kg} \mathrm{~m}^{-1} \mathrm{~s}^{-1}$. As the threshold increases, the fraction of events attributable to ARs lowers (Fig. 6a). More specifically, a $40 \%$ increase in IVT threshold (from 250 to $350 \mathrm{~kg} \mathrm{~m}^{-1} \mathrm{~s}^{-1}$ ) results in a $25 \%$ decrease in identified ARs in the south region but only a $5 \%$ decrease in identified ARs in the west region. With a threshold value of $350 \mathrm{~kg} \mathrm{~m}^{-1} \mathrm{~s}^{-1}$, approximately $71 \%$ of the events in the north and $61 \%$ in the south remain associated with ARs, while the number for the west exceeds $92 \%$. We believe these findings illustrate the results are not overly sensitive to the threshold value from the study by Rutz et al. (2014), and that the west region inhibits largest IVT fluxes (also seen in Fig. 4).

Figure $6 \mathrm{~b}$ further illustrates the sensitivity of IVT magnitude for ARs detected in the three regions. The figure shows the density of IVT values for all ARs (above the $250 \mathrm{~kg} \mathrm{~m}^{-1} \mathrm{~s}^{-1}$ threshold) for each region. The IVT values in the detected ARs is lower in the north compared to the south and the west region, consistent with the fact that on average less moisture is transported to higher latitudes. 
TABLE 1. Table with significance test (independent samples $t$ test) for north, west, and south regions.

\begin{tabular}{lccc}
\hline \hline & North & West & South \\
\hline No. of nonevents & 13048 & 13031 & 13048 \\
No. of events & 101 & 118 & 101 \\
Mean NAO index of nonevents & 0.046 & 0.043 & 0.047 \\
Mean NAO index of events & 0.383 & 0.871 & 0.205 \\
Autocorrelation nonevents & 0.871 & 0.104 & 0.873 \\
Autocorrelation events & 0.263 & 902 & 0.058 \\
Effective No. of nonevents & 900 & 95 & 887 \\
Effective No. of events & 58 & $1.90 \times 10^{-14}$ & 89 \\
$p$ value & $4.97 \times 10^{-4}$ & Yes & 0.114 \\
Significant $(0.05$ level) & Yes & No \\
\hline
\end{tabular}

The IVT in the west region is on average higher than in the south region, even though south is lower in latitude than west. However, the west region is the region with highest precipitation extremes (Fig. 1).

\section{b. Large-scale preconditioning}

The EOF and fuzzy cluster analyses are performed to define characteristic large-scale patterns that precondition the atmosphere for anomalous moisture transport and extreme precipitation in Norway.

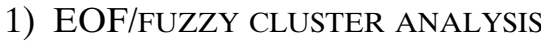

As an illustration of the method, the results of the EOF analysis for the west region $120 \mathrm{~h}$ prior to the event are presented in Fig. 7. The colors represent the average potential temperature (PT) on the dynamic tropopause for all events. The first two principal components are shown as PT anomalies (black contours). Principal component one (PC1) explains the largest variability in the dataset (18.58\%) and principal component two (PC2) the second largest variability $(6.94 \%)$.

The PC anomalies observed in Fig. 7 are largely similar in structure, with two centers of enhanced variability identified in the western and central Atlantic basin. The primary difference between the $\mathrm{PC} 1$ and $\mathrm{PC} 2$ patterns is in the sign and the magnitude of the anomalies: a positive-positive and a positive-negative couplet for $\mathrm{PC} 1$ and $\mathrm{PC} 2$, respectively. $\mathrm{PC} 1$ represents a meridional displacement in the PT gradient, while PC2 is associated with a meridionally amplified flow pattern.

The first two principal components provide a framework for the fuzzy cluster analysis. Figure 8 shows the clustering of the events in the PC1-PC2 phase space, where each event is represented by a unique PC1-PC2 value. The primary difference between the two clusters is the values of PC1. Please note that not all events are placed in a cluster. The events that do not belong to a cluster will not be included in the subsequent analyses.
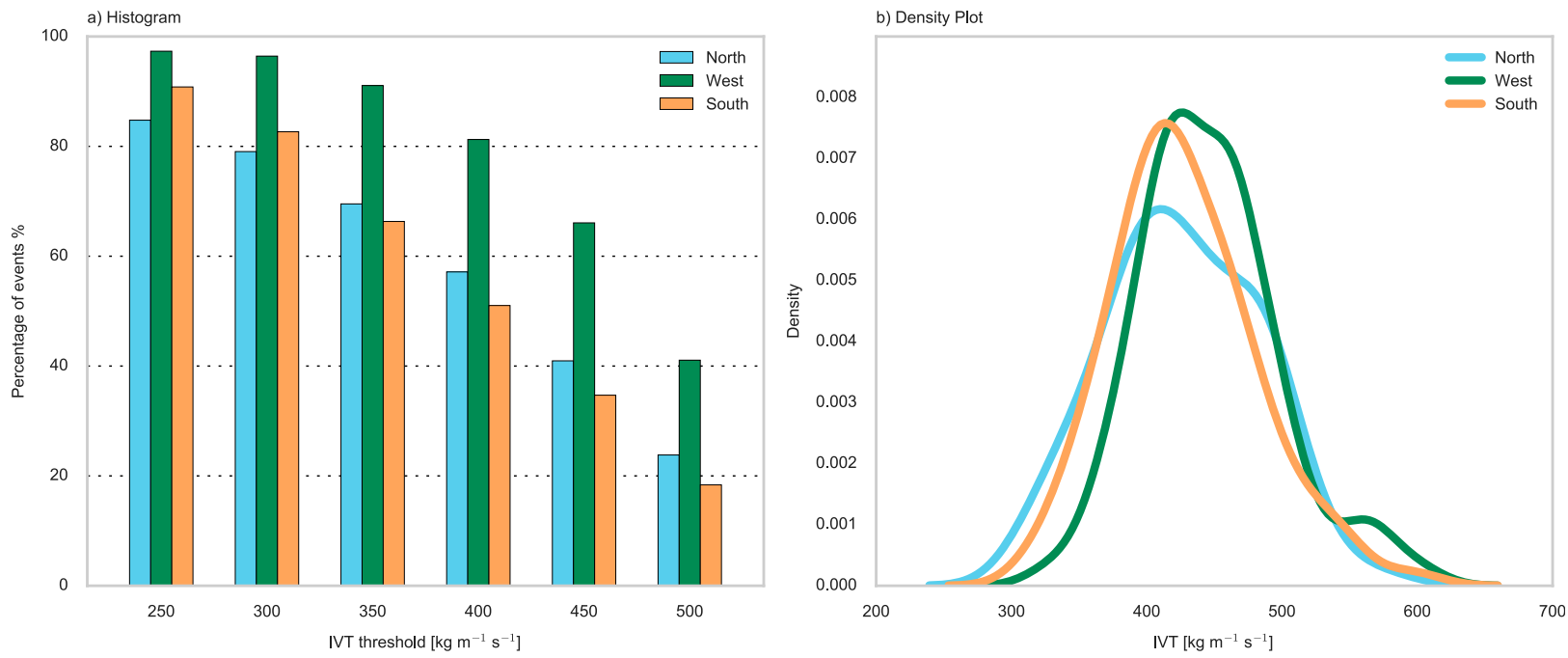

FIG. 6. (a) Percentage of identified atmospheric rivers compared to total events for the three regions (north, west, and south) by changing the IVT threshold from default $\left(250 \mathrm{~kg} \mathrm{~m}^{-1} \mathrm{~s}^{-1}\right)$ to $500 \mathrm{~kg} \mathrm{~m}^{-1} \mathrm{~s}^{-1}$ with increasing steps of $50 \mathrm{~kg} \mathrm{~m}^{-1} \mathrm{~s}^{-1}$. (b) Density plot of IVT values for ARs detected (above $250 \mathrm{~kg} \mathrm{~m}^{-1} \mathrm{~s}^{-1}$ ) in each region. 
a)

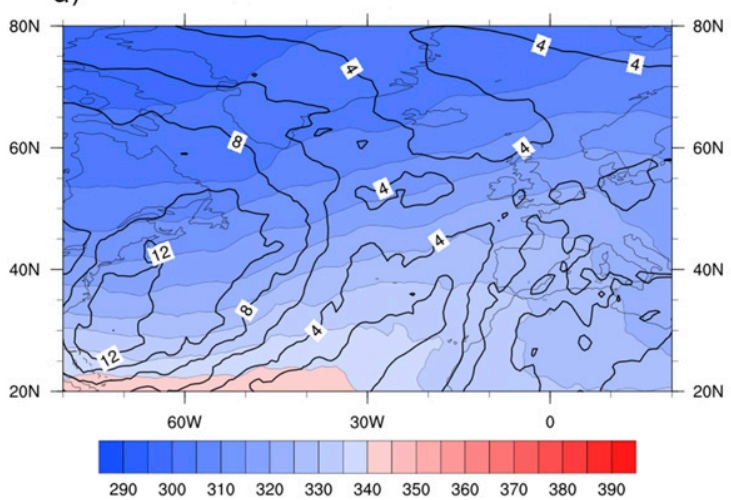

b)

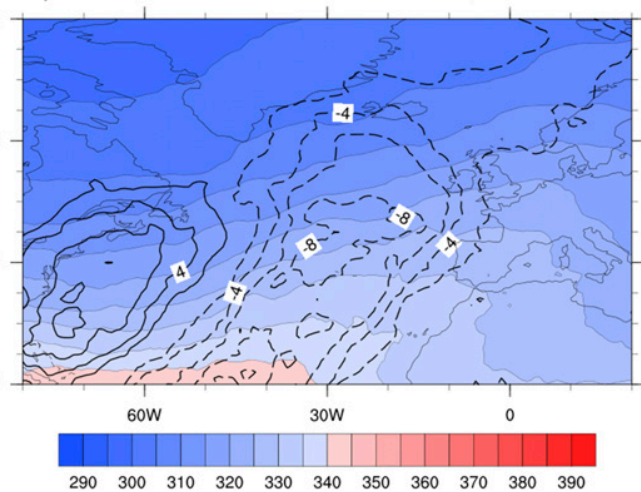

FIG. 7. Spatial EOF patterns (contoured at an interval of $1.0 \mathrm{~K}$, negative contours are dashed) for potential temperature on the 2-PVU $\left(1 \mathrm{PVU}=10^{-6} \mathrm{~K} \mathrm{~kg}^{-1} \mathrm{~m}^{2} \mathrm{~s}^{-1}\right)$ surface for the west region $120 \mathrm{~h}$ prior to the actual event for (a) EOF 1 (which explains $18.6 \%$ of the variability) and (b) EOF 2 (which explains $6.9 \%$ of the variability). The average potential temperature $(\mathrm{K})$ is shaded.

The composite structure of the PT on the dynamic tropopause for the clustered events is presented in Fig. 9 for both clusters. Cluster one is characterized by an intense southward shifted jet (large PT gradient of $70 \mathrm{~K}$ over $30^{\circ}$ latitude) over North America and the western Atlantic. The jet exhibits a southwest-northeast orientation toward western Europe and Norway, with a weakening of the jet going eastward (smaller PT gradient of $30 \mathrm{~K}$ over $30^{\circ}$ latitude over England, Fig. 9a). Although we cannot confirm this from the composite plot, the observed structure in the eastern Atlantic is consistent with the presence of anticyclonic wave breaking. The reversal of the meridional gradient of PT is not immediately evident, likely due to the compositing of a number of wave breaking events; however an analysis of individual events lends credence to the veracity of the statement. In contrast to cluster one, cluster two is characterized by a weak northward shifted jet (smaller PT gradient of $45 \mathrm{~K}$ over $30^{\circ}$ latitude). This jet is primarily zonal in nature, with very little undulation across the Atlantic basin (Fig. 9b).

\section{2) Composite ANALYsis}

We will primarily focus on west Norway, as this region exhibits both the largest precipitation amounts and the highest fraction of ARs. The cluster composites of MSLP, daily precipitation and IVT magnitude and vector are presented for the time steps $120,72,24$, and $0 \mathrm{~h}$ before the event (Fig. 10).

For both clusters and all time steps, the MSLP pattern exhibits a similar couplet with a negative anomaly to the north inferring low pressure and a positive anomaly to the south inferring high pressure. The result is inferred lowlevel flow across the Atlantic basin which is conducive to moisture transport toward western Europe and Norway in particular. The primary difference between the two cluster composites is in the orientation of the pressure centers. At $120 \mathrm{~h}$, a low pressure center is located off the east coast of Greenland in both clusters. A high pressure center is located in the eastern (western) Atlantic for cluster one (two). Consistent with the dynamic tropopause analysis (Fig. 9), cluster one exhibits inferred lowlevel flow from the southwest to the northeast, whereas cluster two is characterized by westerly flow.

As the time before the events occur decreases, the two clusters converge to a similar structure in the eastern

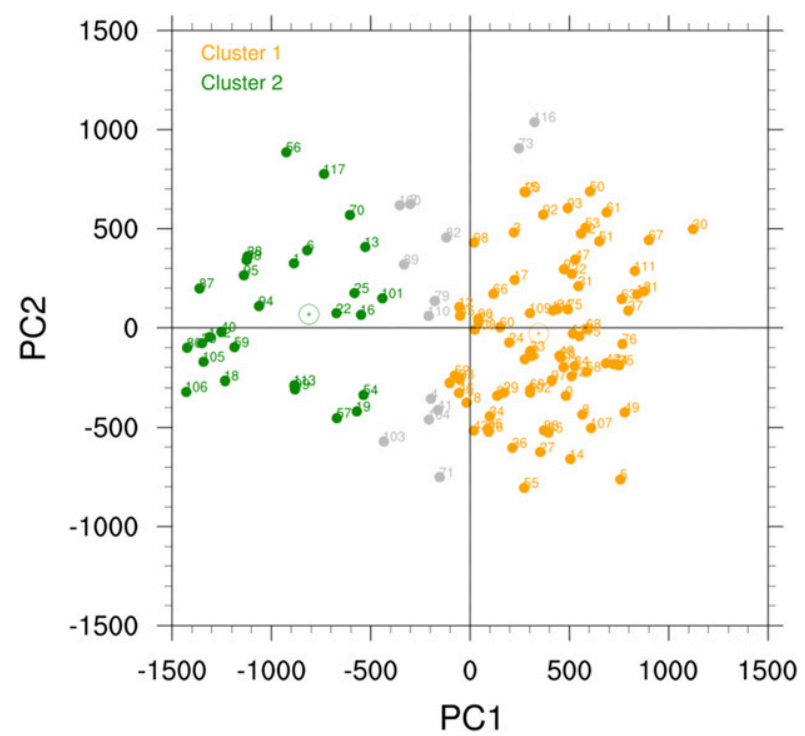

FIG. 8. The first and second principal component phase space with the two-cluster solution for the events selected for the west region $120 \mathrm{~h}$ prior to the actual event. Each dot represents a selected event. The light gray points define events that do not belong to any cluster. The circles with the small dots are the cluster centers. 

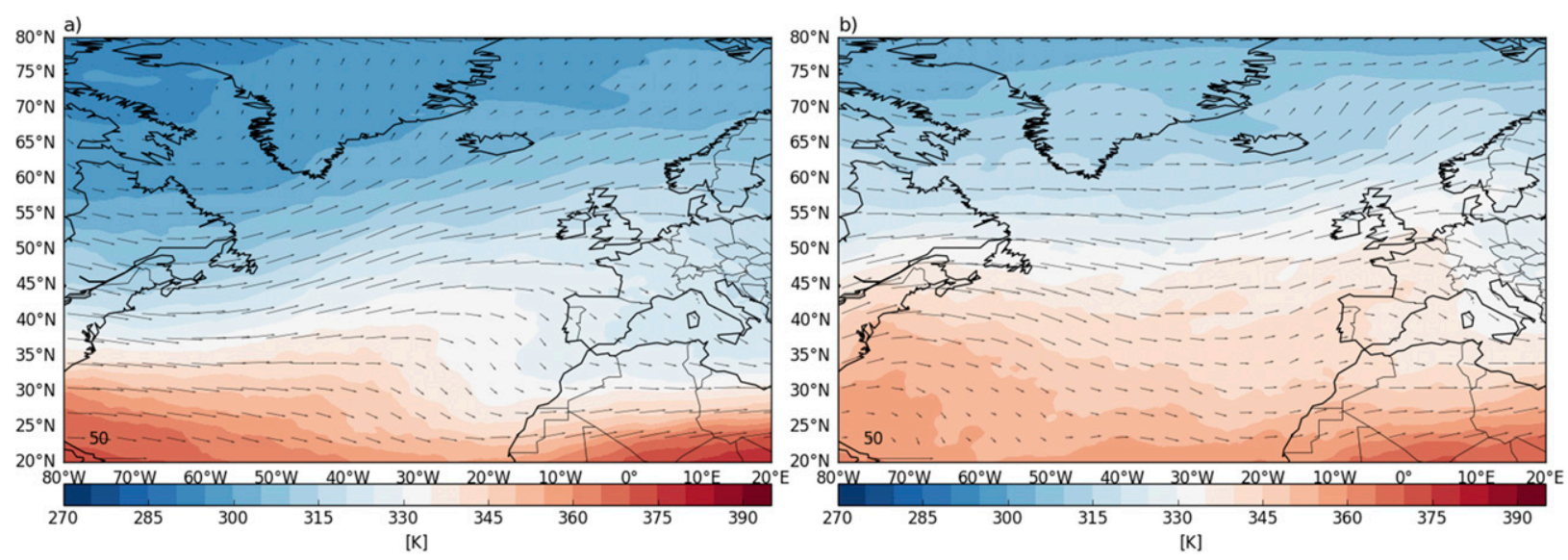

FIG. 9. Composite analysis of potential temperature at the tropopause in $\mathrm{K}$ and wind vectors for the west region $120 \mathrm{~h}$ prior to the actual event for (a) cluster one and (b) cluster two.

Atlantic/western Europe, with a low pressure center between Iceland and Norway and a high pressure center over western Europe. At the time of the event, both clusters exhibit strong flow with a southwesterly component impinging upon the mountainous terrain of southwestern Norway. Given the extreme precipitation that defines the events and consistent with case study analyses, it is logical to assume an orographic enhancement of precipitation due to the conducive flow pattern.

There are minor differences between the clusters, even on the day of the event. The inferred low-level flow is both more westerly and stronger (larger pressure gradient force) for cluster one. In contrast, cluster two exhibits a more southerly component and weaker flow. Both flow patterns are reminiscent of a positive NAO, however, the more meridional and weaker flow observed in cluster two may indicate a larger fraction of negative NAO events for cluster two. Further work would be needed to confirm this result.

In addition, the cluster composites of MSLP, daily precipitation and IVT magnitude and vectors for the north and south regions at time steps 120 and $24 \mathrm{~h}$ before the event are presented in Fig. 11. At $120 \mathrm{~h}$, the qualitative structure of the composites is similar to those for the west region. A low pressure center is observed to the east of Greenland and high pressure to the south. The placement of the high pressure system is also comparable, with a tendency for the highest pressure to be in the eastern (western) Atlantic for cluster one (two). Both cluster patterns result in significant moisture transport across the Atlantic basin.

Given the clear link between extreme precipitation in Norway and ARs and the context of previous work on the topic of AR dynamics and predictability, the similarity of the cluster analyses for the three regions $120 \mathrm{~h}$ before the event is expected. The large-scale structure must be conducive to anomalous moisture transport toward Norway for an extreme event to occur. That there are two relatively distinct patterns is consistent with Sodemann and Stohl (2013) and the known characteristic life cycles of baroclinic waves. This point will be raised in further detail in the following section.

At $24 \mathrm{~h}$ before the event, regional differences are more pronounced and, as also in the west composites, the two clusters for each region become more similar. The north region composites show southwesterly flow between Iceland and Great Britain. The south region composites exhibit a southerly component of the flow toward southern Norway. Both regional patterns are consistent with moisture transport toward the area of extreme precipitation. Logically, as the flow pattern during events for each region must be similar to result in extreme precipitation in that region.

The EOF/fuzzy cluster/composite results highlight previously reported facets of the predictability of extreme precipitation associated with ARs. The presence and general location of ARs are well predicted in today's numerical weather prediction systems as they are directly tied to the large-scale flow patterns which are inherently more predictable (Dettinger 2011). While this study incorporates a reanalysis dataset rather than forecast data, we believe the synoptic-scale indicators out to $120 \mathrm{~h}$ identified herein will be reasonably consistent with today's state-of-the-art global forecast models.

\section{Discussion and conclusions}

This study presents a climatology of cold season extreme precipitation events for Norway from 1979 to 

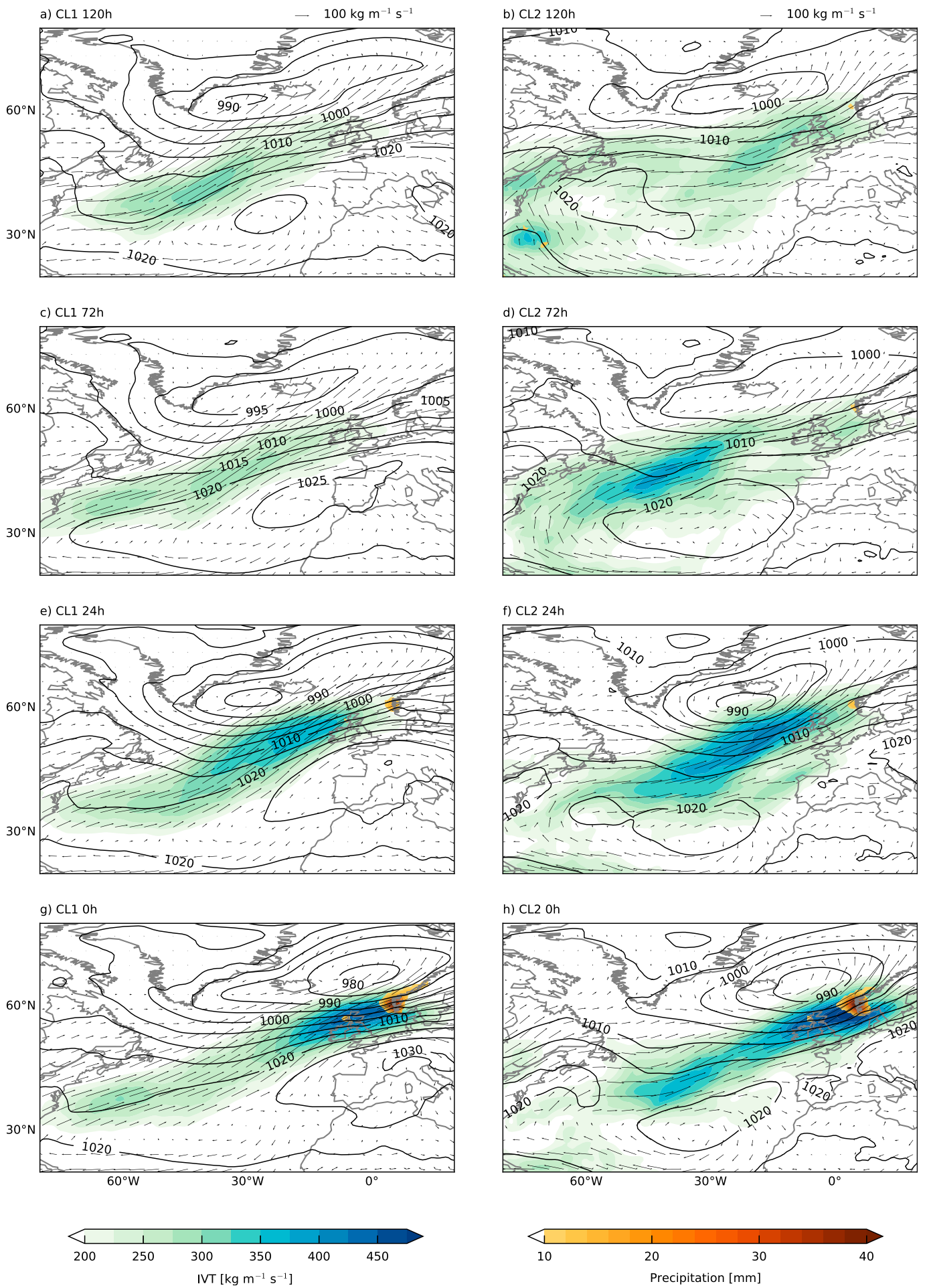

FIG. 10. Composites of mean sea level pressure (hPa) in contours and total precipitation $(\mathrm{mm})$ in orange-red shading and IVT vectors and magnitude $\left(\mathrm{kg} \mathrm{m}^{-1} \mathrm{~s}^{-1}\right)$ in green-blue shading at 120,72 , and $24 \mathrm{~h}$ before the event and at the actual event itself $(0 \mathrm{~h})$ for the two clusters (CL1 and CL2) for the west region: (left) cluster one and (right) cluster two. 

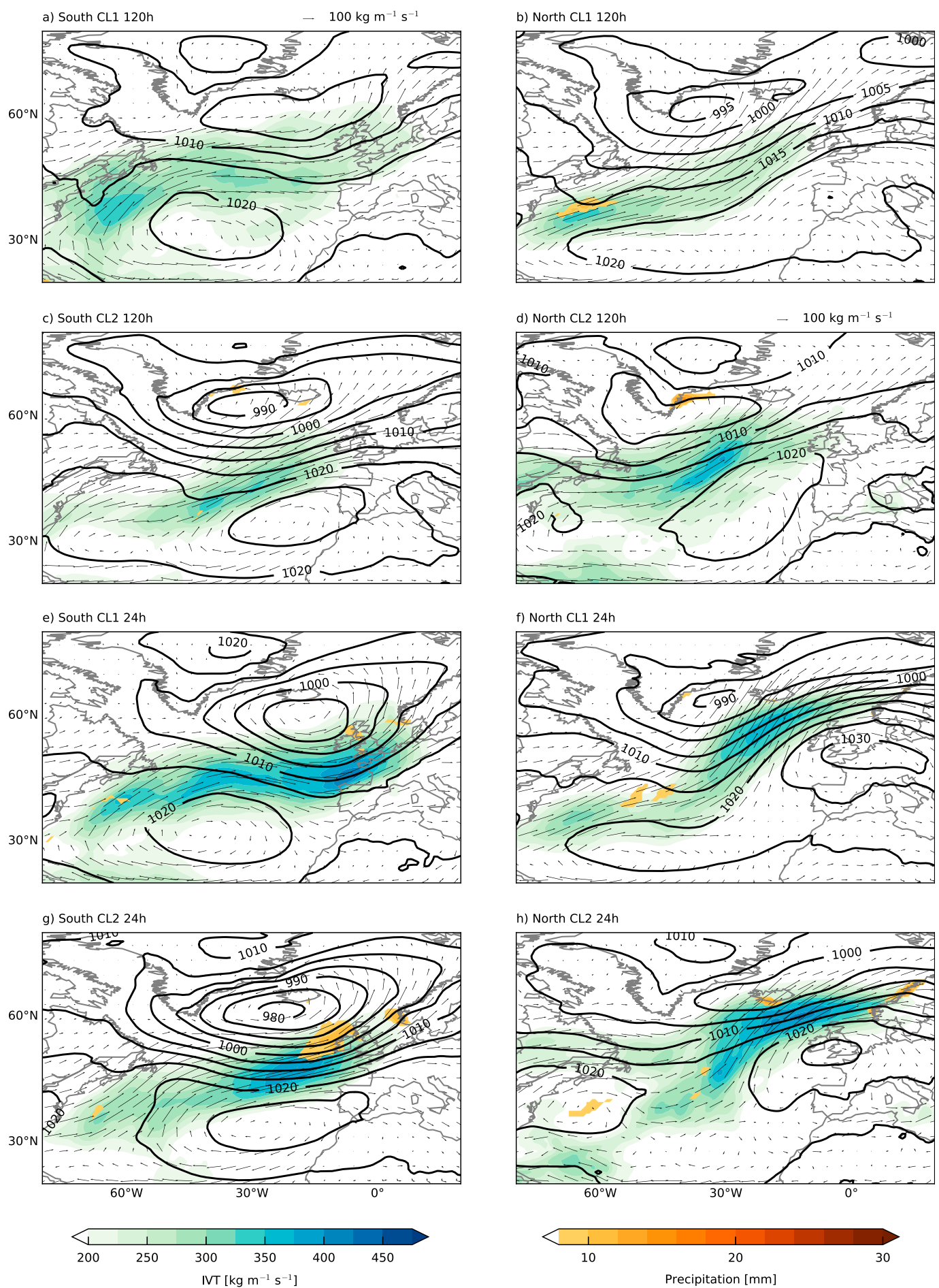

FIG. 11. Composites of mean sea level pressure $(\mathrm{hPa})$ in contours and total precipitation $(\mathrm{mm})$ in orange-red shading and IVT vectors and magnitude $\left(\mathrm{kg} \mathrm{m}^{-1} \mathrm{~s}^{-1}\right)$ in green-blue shading at (top four panels) $120 \mathrm{~h}$ and (bottom four panels) $24 \mathrm{~h}$ before the event, for the two clusters (CL1 and CL2) for the (left) south region and (right) north region. 
2014, based on the 99th percentile of area-averaged precipitation from ERA-Interim. Three regions are identified: north and west regions exhibit a climatological maxima in precipitation, and a south region is based upon previous cases of extreme weather. The performance of ERA-Interim in simulating precipitation over Norway is not studied in detail here, as we focus on the large-scale processes related to these extreme precipitation events.

Consistent with previous work, we found that extreme precipitation events are more frequent during the positive phase of the NAO. These results are statistically significant at the 0.05 threshold for the north and west regions, while no statistical significance was found for the south. Additionally, there is a statistically significant correlation of monthly events (number of events occurring per month) for all three couplets (west-north, west-south, north-south). This indicates an increased likelihood of an event in a region during a month wherein an event occurs in another region.

An overarching hypothesis of this work is that anomalous moisture transport, or so-called ARs, are critical to cold season extreme precipitation in Norway. An objective analysis illustrates that more than $85 \%$ of events are linked to ARs, and that the causal link is not overly sensitive to the subjective threshold of $250 \mathrm{~kg} \mathrm{~m}^{-1} \mathrm{~s}^{-1}$ integrated vapor transport provided by Rutz et al. (2014).

EOF and fuzzy cluster analyses are performed to define the characteristic synoptic-scale patterns that lead to extreme precipitation over Norway. Multiple days before the event $(120 \mathrm{~h})$, two patterns are identified, for all regions. The first represents an intense, southward shifted jet that exhibits a southwest-northeast orientation. The second identifies a weak, northward shifted jet that is zonal in structure.

This finding can be directly compared to the results of Sodemann and Stohl (2013), who examined the month of December 2006 which was characterized by well above average temperature and precipitation in Norway. They subjectively identified two moisture transport configurations associated with the characteristic life cycles of baroclinic waves: (i) anticyclonic wave breaking associated with a meridional jet and (ii) cyclonic wave breaking associated with a zonal jet. The objective patterns found herein are consistent with their schematic representation.

It would be of interest to further explore the link between anomalous moisture transport and wave breaking (Hu et al. 2017). Momentum fluxes associated with wave breaking are important to the jet strength and structure and are typically conducive toward maintaining the orientation of the jet and, hence, the type of wave breaking. These fluxes can imply some measure of predictability that may be exploited.

As the time before the events occur decreases, the similarity of the two patterns for each region lessens. The distinctive flow pattern conducive to orographically enhanced precipitation emerges in the two clusters for each region. For the north and west regions, this entails primarily zonal flow impinging upon the southnorth orientated topography, the difference being the latitude of the strong flow. In contrast, the south region exhibits a significant southerly component to the flow. Taken as a whole, the results of this work confirm that similar large-scale flow patterns as identified in the Pacific basin and North America are relevant to Norwegian extreme precipitation events. The overwhelming majority of events (more than $85 \%$ ) are associated with ARs. Characteristic patterns conducive to anomalous moisture transport can be identified with significant time before the event (5 days), which is helpful to and can improve forecasting. However, the identification of large-scale patterns 5 days before the event is insufficient to predict the precise location of subsequent extreme precipitation.

Given the limited resolution of the reanalysis data employed, little can be said regarding the sensitivity of the mesoscale structure of precipitation, which ultimately defines the sensible weather impact. Future work will attempt to explore the direct link between ARs and flooding, landslides and avalanches associated with extreme precipitation in Norway.

Acknowledgments. We thank Patrick Harr and Julian Quinting for providing the EOF/fuzzy cluster script and Anne Fouilloux for her significant contributions regarding data acquisition and analysis. Funding has been provided by the Research Council of Norway in association with the FlomQ project under the ENERGIX program. Imme Benedict would like to thank the Norwegian Meteorological Institute for providing and supporting an internship.

\section{REFERENCES}

Azad, R., and A. Sorteberg, 2017: Extreme daily precipitation in coastal western Norway and the link to atmospheric rivers. J. Geophys. Res. Atmos., 122, 2080-2095, https://doi.org/ 10.1002/2016JD025615.

Bader, M., and W. Roach, 1977: Orographic rainfall in warm sectors of depressions. Quart. J. Roy. Meteor. Soc., 103, 269-280, https://doi.org/10.1002/qj.49710343605.

Brands, S., J. Gutiérrez, and D. San-Martín, 2017: Twentiethcentury atmospheric river activity along the west coasts of Europe and North America: Algorithm formulation, reanalysis uncertainty and links to atmospheric circulation patterns. Climate Dyn., 48, 2771-2795, https://doi.org/10.1007/s00382-016-3095-6. 
Browning, K., and C. Pardoe, 1973: Structure of low-level jet streams ahead of mid-latitude cold fronts. Quart. J. Roy. Meteor. Soc., 99, 619-638, https://doi.org/10.1002/qj.49709942204.

Dee, D., and Coauthors, 2011: The ERA-Interim reanalysis: Configuration and performance of the data assimilation system. Quart. J. Roy. Meteor. Soc., 137, 553-597, https://doi.org/10.1002/qj.828.

Dettinger, M., 2011: Climate change, atmospheric rivers, and floods in California-A multimodel analysis of storm frequency and magnitude changes. J. Amer. Water Resour. Assoc., 47, 514523, https://doi.org/10.1111/j.1752-1688.2011.00546.x.

Harr, P. A., D. Anwender, and S. C. Jones, 2008: Predictability associated with the downstream impacts of the extratropical transition of tropical cyclones: Methodology and a case study of Typhoon Nabi (2005). Mon. Wea. Rev., 136, 3205-3225, https://doi.org/10.1175/2008MWR2248.1.

Harrold, T., 1973: Mechanisms influencing the distribution of precipitation within baroclinic disturbances. Quart. J. Roy. Meteor. Soc., 99, 232-251, https://doi.org/10.1002/qj.49709942003.

Heikkilä, U., and A. Sorteberg, 2012: Characteristics of autumnwinter extreme precipitation on the Norwegian west coast identified by cluster analysis. Climate Dyn., 39, 929-939, https://doi.org/10.1007/s00382-011-1277-9.

Hu, H., F. Dominguez, Z. Wang, D. A. Lavers, G. Zhang, and F. M. Ralph, 2017: Linking atmospheric river hydrological impacts on the U.S. West Coast to Rossby wave breaking. J. Climate, 30, 3381-3399, https://doi.org/10.1175/JCLI-D-16-0386.1.

Knippertz, P., and H. Wernli, 2010: A Lagrangian climatology of tropical moisture exports to the Northern Hemispheric extratropics. J. Climate, 23, 987-1003, https://doi.org/10.1175/ 2009JCLI3333.1.

Lavers, D. A., and G. Villarini, 2013: The nexus between atmospheric rivers and extreme precipitation across Europe. Geophys. Res. Lett., 40, 3259-3264, https://doi.org/10.1002/grl.50636.

—, R. P. Allan, E. F. Wood, G. Villarini, D. J. Brayshaw, and A. J. Wade, 2011: Winter floods in Britain are connected to atmospheric rivers. Geophys. Res. Lett., 38, L23803, https:// doi.org/10.1029/2011GL049783.

Leung, L. R., and Y. Qian, 2009: Atmospheric rivers induced heavy precipitation and flooding in the western U.S. simulated by the WRF regional climate model. Geophys. Res. Lett., 36, L03820, https://doi.org/10.1029/2008GL036445.

McTaggart-Cowan, R., J. R. Gyakum, and R. W. Moore, 2017: The baroclinic moisture flux. Mon. Wea. Rev., 145, 25-47, https:// doi.org/10.1175/MWR-D-16-0153.1.

Ralph, F. M., and M. Dettinger, 2011: Storms, floods, and the science of atmospheric rivers. Eos, Trans. Amer. Geophys. Union, 92, 265-266, https://doi.org/10.1029/2011EO320001.

, P. J. Neiman, and G. A. Wick, 2004: Satellite and CALJET aircraft observations of atmospheric rivers over the eastern
North Pacific Ocean during the winter of 1997/98. Mon. Wea. Rev., 132, 1721-1745, https://doi.org/10.1175/1520-0493(2004) $132<1721$ :SACAOO $>2.0 . \mathrm{CO} ; 2$.

,,,--- S. I. Gutman, M. D. Dettinger, D. R. Cayan, and A. B. White, 2006: Flooding on California's Russian River: Role of atmospheric rivers. Geophys. Res. Lett., 33, L13801, https://doi.org/10.1029/2006GL026689.

, G. N. Kiladis, K. Weickmann, and D. W. Reynolds, 2011: A multiscale observational case study of a Pacific atmospheric river exhibiting tropical-extratropical connections and a mesoscale frontal wave. Mon. Wea. Rev., 139, 11691189, https://doi.org/10.1175/2010MWR3596.1.

Richman, M. B., 1986: Rotation of principal components. J. Climatol., 6, 293-335, https://doi.org/10.1002/joc.3370060305.

Rutz, J. J., W. J. Steenburgh, and F. M. Ralph, 2014: Climatological characteristics of atmospheric rivers and their inland penetration over the western United States. Mon. Wea. Rev., 142, 905-921, https://doi.org/10.1175/MWR-D-13-00168.1.

Sodemann, H., and A. Stohl, 2013: Moisture origin and meridional transport in atmospheric rivers and their association with multiple cyclones. Mon. Wea. Rev., 141, 2850-2868, https://doi.org/10.1175/MWR-D-12-00256.1.

Stohl, A., C. Forster, and H. Sodemann, 2008: Remote sources of water vapor forming precipitation on the Norwegian west coast at $60^{\circ} \mathrm{N}-\mathrm{A}$ tale of hurricanes and an atmospheric river. J. Geophys. Res., 113, D05102, https://doi.org/10.1029/ 2007JD009006.

Thorncroft, C., B. Hoskins, and M. McIntyre, 1993: Two paradigms of baroclinic-wave life-cycle behaviour. Quart. J. Roy. Meteor. Soc., 119, 17-55, https://doi.org/10.1002/qj.49711950903.

Ummenhofer, C. C., H. Seo, Y.-O. Kwon, R. Parfitt, S. Brands, and T. M. Joyce, 2017: Emerging European winter precipitation pattern linked to atmospheric circulation changes over the North Atlantic region in recent decades. Geophys. Res. Lett., 44, 8557-8566, https://doi.org/10.1002/ 2017GL074188.

Uvo, C. B., 2003: Analysis and regionalization of northern European winter precipitation based on its relationship with the North Atlantic Oscillation. Int. J. Climatol., 23, 1185-1194, https://doi.org/10.1002/joc.930.

Wick, G. A., P. J. Neiman, F. M. Ralph, and T. M. Hamill, 2013: Evaluation of forecasts of the water vapor signature of atmospheric rivers in operational numerical weather prediction models. Wea. Forecasting, 28, 1337-1352, https://doi.org/10.1175/ WAF-D-13-00025.1.

Zhu, Y., and R. E. Newell, 1998: A proposed algorithm for moisture fluxes from atmospheric rivers. Mon. Wea. Rev., 126, 725-735, https://doi.org/10.1175/1520-0493(1998)126<0725: APAFMF $>2.0 . \mathrm{CO} ; 2$. 